\title{
Carta de Presentación:
}

El número 4 del Journal de Ciencias Sociales , Revista Académica de la Facultad de Ciencias Sociales de la Universidad de Palermo, Argentina, nos presenta cinco artículos científicos, dos ensayos y las notas correspondientes a las Secciones "Reseña de Libros "y "Política Internacional", incluyendo como novedad una nueva sección titulada "Rescate".

Nuestros autores provienen de distintas disciplinas, la Ciencia Política, la Geografía, la Filosofía, la Historia, las Relaciones Internacionales, la Psicología.

El primer artículo de nuestros colegas del CONICET Juan Pablo Celemín y Guillermo Velázquez se refiere a la calidad de vida y la pobreza en Argentina proponiendo la elaboración de un índice que busca establecer el grado de asociación con el tradicional indicador de Necesidades Básicas Insatisfechas.

El segundo artículo escrito por Agustina Grigera, Bernardo Pascale y Rosendo Alsina presenta los primeros resultados de una serie de mediciones acerca del capital social realizadas por el Observatorio de Capital Social de la Universidad de Palermo y de la Consultora Carlos Fara y Asociados, centrados en la reflexión sobre la confianza interpersonal y en las instituciones, así como en los atributos considerados relevantes para ser un buen ciudadano en la Argentina.

A continuación se presenta el ensayo de Pablo Zanor que reflexiona sobre el malestar del sujeto en la sociedad de consumo y señala la fractura entre la conciencia personal y la sociedad como la causa del desencanto del sujeto con él mismo y con lo institucional, señalando que la sociedad moderna, preocupada por la producción y el consumo habría olvidado precisamente a la persona misma y el tratamiento de temas fundamentales tales como la relación varón/mujer, la educación, el sufrimiento y la muerte, la justicia y la culpa .

El artículo que nos hace llegar el colega de Chile, Andrés Cabezas Corccione titulado Valores Motivacionales y Bienestar Subjetivo en Profesionales Chilenos se dedica a la evaluación del nivel de incidencia que presentan los valores motivacionales y sus componentes, sobre el bienestar subjetivo de profesionales que se desempeñan en empresas privadas de Santiago de Chile.

Desde México, Sergio Hernández Galindo con su ensayo titulado Migración japonesa y guerra: Fernando Hiramuro, un hibakusha mexicano, muestra trazos de la historia familiar de un emigrante japonés radicado en México, cuya vida concentra procesos históricos de más largo alcance que llevaron al traslado de cientos de miles de migrantes de ese país al continente Americano.

El artículo de Miguel Recondo acerca de los dispositivos estructurales de la acción colaborativa en contextos de integración regional, presenta un análisis de casos, aplicada al campo de la innovación 
tecnológica e institucional, tomando dos procesos relevantes: el distrito industrial del municipio de Santa Rita, Estado de Minas Gerais, Brasil, que incluye al Instituto de Telecomunicaciones- INATEL y su Polo Científico y Tecnológico, y el sistema universitario- tecnológico del Estado de Georgia, en EUA con su iniciativa Yamacraw, y su despliegue en los últimos 20 años.

Finalmente el artículo de Matías Gordziejczuk titulado Exploración sobre la revalorización rural y la calidad de vida en el partido de General Pueyrredon (Sudeste de la provincia de Buenos Aires, Argentina) estudia el caso de las estancias turísticas La Reserva y La Trinidad y nos invita a explorar el proceso contemporáneo de revalorización del espacio rural a partir de un análisis centrando en su capacidad creciente de absorber flujos de población impulsados por la necesidad de ocio y turismo.

A continuación el Journal presenta sus dos secciones "Reseña de libros" y "Política Internacional" y a partir de este número incorpora una nueva sección titulada "Rescate" cuyo sentido es recuperar textos científicos o ensayísticos no recientes, pero todavía actuales cuyo eje estructural sea la interdisciplinariedad.

Con mi agradecimiento a los/as autores y autoras que han colaborado en este nuevo número, los/ as invito a leer el número 4 del Journal de Ciencias Sociales Revista Académica de la Facultad de Ciencias Sociales de la Universidad de Palermo, Argentina.

Dra. Graciela Tonon

Directora 